\title{
A new strategy for specific imaging of neural cells based on peptide-conjugated gold nanoclusters
}

\author{
This article was published in the following Dove Press journal: \\ International Journal of Nanomedicine \\ 16 March 2015 \\ Number of times this article has been viewed
}

\section{Enqi Zhang \\ Ailing Fu}

School of Pharmaceutical Sciences, Southwest University, Chongqing, People's Republic of China
Correspondence: Ailing Fu School of Pharmaceutical Sciences, Southwest University, Tiansheng Road, Beibei District, Chongqing, 4007/6, People's Republic of China Tel +86 0236825 I225

Fax +86023 $6825 \quad 1225$

Email fuailing1008@hotmail.com

\begin{abstract}
Despite the significant progress in molecular imaging technologies that has been made in recent years, the specific detection of neural cells still remains challenging. Here, we suggest the use of gold nanoclusters (AuNCs) modified with a brain-targeting peptide as a potential imaging candidate for detecting neural cells in vitro and in mice. AuNCs of less than $10 \mathrm{~nm}$ (dynamic light scattering analysis) were first prepared using the "green" synthetic approach, and then a targeting peptide, rabies virus glycoprotein derived peptide (RDP), was conjugated to the AuNCs for improving the efficiency and specificity of neural cell penetration. The conjugate's mechanism of cellular attachment and entry into neural cells was suggested to be receptor-mediated endocytosis through clathrin-coated pits. Also, noninvasive imaging analysis and animal studies indicated that the RDP-modified nanoclusters could concentrate in the brain and locate in neural cells. This study suggests the feasibility of using targeting peptide-modified nanoclusters for noninvasive imaging brain cells in vivo.
\end{abstract}

Keywords: RDP, targeted delivery, bioimaging, brain

\section{Introduction}

Noninvasive imaging of the neural cells of the central nervous system is a promising strategy for theranostics, however, it still remains challenging due to some drawbacks such as low signal-to-noise ratio resulting from the scattering of fluorescence signals by thick brain tissues ${ }^{1,2}$ and low strict single-cell resolution. ${ }^{3}$ The principal barriers to detecting neural cells in vivo are the tissue specificity of fluorescence-based imaging and the poor cell penetration ability of materials used in the neural cell imaging to blood-brain barrier (BBB). ${ }^{4-6}$ To address these problems, the coupling of a specific BBB-penetrating carrier and stable fluorescence payload to achieve live and long-term imaging of neural cells may provide new insights that will help elucidate the essential structural and functional information in central nervous system disorders and then to observe and control the relative diseases.

Gold nanomaterials of sizes less than $10 \mathrm{~nm}$, providing a variety of platforms for the interaction of nanoparticles with biomolecules, ${ }^{7}$ have been used in various fields either for diagnostic purposes, including imaging, ${ }^{8,9}$ the turning on and off of the near-infrared fluorescent bioimaging of cells, ${ }^{10}$ biological labeling, ${ }^{11}$ electrochemical genosensors for DNA, ${ }^{12}$ and for cancer therapy as multifunctional nanomedicines with noninvasive in vivo near-infrared fluorescence capability. ${ }^{13}$ Low toxicity and the ultrafine size of gold nanomaterials have captivated the interest of researchers and are indicated as potential candidates for passage through the BBB. ${ }^{14}$ Gold nanoclusters (AuNCs), especially, one small-size gold nanomaterial, with high quantum yields, have been used for molecular location research, both in vitro ${ }^{15,16}$ and in vivo. ${ }^{17}$ However, the application of AuNCs is limited due to the lack of cell specificity and a widespread 
distribution in vivo, ${ }^{18}$ so the surface of AuNCs should be modified to improve cell selectivity in case of bioimaging applications.

Our group recently developed a brain-targeting peptide, rabies virus glycoprotein derived peptide (RDP) ${ }^{19}$ - a long peptide consisting of 39 amino acids, which is derived from 330-357 amino acid sequences of the rabies virus glycoprotein, one of the key candidates for mediating the virus into host cells. ${ }^{20}$ RDP has been suggested to be able to deliver several proteins and DNA into the mouse brain, including brain-derived neurotrophic factor (BDNF), glial cell-derived neurotrophic factor (GDNF), plasmids containing Lac Z, and the BDNF gene. Also, repeated administration of RDP and its conjugates does not produce obvious toxicity or immunogenicity in the animals. ${ }^{21,22}$ Therefore, we assumed that RDP could be used as a safe targeting ligand in vivo after AuNCs surface modification.

In this study, RDP was attached to the surface of AuNCs for long-term, nontoxic imaging and neural-cell targeting in living cells and in mice. The novel peptide-conjugated AuNCs (RDP-AuNCs) were characterized by using Fouriertransform infrared (FTIR) spectroscopy, dynamic light scattering (DLS), zeta-potential analysis, gel electrophoresis, as well as ultraviolet (UV)-visible spectroscopy. The localization of RDP-AuNCs in neural cells was determined by transmission electron microscopy (TEM), and the mechanism of cellular attachment and entry into the neural cells of the conjugates was determined to be receptor-mediated endocytosis through clathrin-coated pits. Both noninvasive imaging analysis and in vivo animal tests suggested that the RDP-AuNCs are an effective and specific bioimaging agent for neural cells.

\section{Materials and methods Preparation of fluorescent gold nanoclusters and RDP-gold nanoclusters}

Bovine serum albumin (BSA)-coated AuNCs were prepared according to a previous report. ${ }^{23}$ Briefly, BSA solution $\left(2 \mathrm{~mL}, 50 \mathrm{mg} / \mathrm{mL}\right.$ ) was refluxed for 5 minutes at $37^{\circ} \mathrm{C}$, and then $\mathrm{HAuCl}_{4}$ aqueous solution $(2 \mathrm{~mL}, 10 \mathrm{mM}$ ) was slowly added under vigorous stirring. Five minutes later, $\mathrm{NaOH}$ solution $(0.18 \mathrm{~mL}, 1 \mathrm{M})$ was introduced, and the mixture was refluxed at $37^{\circ} \mathrm{C}$ for another 12 hours until a deep brown solution was obtained. The solution was centrifuged at $17,000 \times g$ for 30 minutes, then dialyzed (using a 2,000 molecular weight cut-off [MWCO] dialysis membrane) against Milli-Q ${ }^{\circledR}$ water for at least 24 hours with periodic changes of the water to remove any small impurities. Subsequently, the dialyzed solution was filtered by using $0.22 \mu \mathrm{m}$ syringe filters to remove precipitates. Finally, the AuNCs product was stored at $4^{\circ} \mathrm{C}$.

To prepare the RDP-AuNCs conjugates, RDP stock solution $(2 \mathrm{mg} / \mathrm{mL}, 500 \mu \mathrm{L})$ was slowly dropped into the AuNCs solution $(2 \mathrm{~mL})$. The RDP/AuNCs mixture was incubated and gently mixed overnight at $25^{\circ} \mathrm{C}$ to obtain the RDP-AuNCs. The conjugate was then centrifuged at $17,000 \times g$ for 30 minutes and filtered using $0.22 \mu \mathrm{m}$ syringe filters. The mixture was dialyzed against Milli-Q water for 2 days to remove the excess RDP. The purified RDP-AuNCs were stored at $4^{\circ} \mathrm{C}$ for frequent use or freeze-dried for storage.

The same preparation process was followed to produce gold nanoclusters modified with carboxyfluorescein (FAM) labeled rabies virus glycoprotein derived peptide (FAMRDP-AuNCs), except FAM-labeled RDP (synthesized by Shanghai Ji'er Biotech Co, Shanghai, China) was used instead of RDP. As a control for in vivo imaging, a gold nanoparticle (AuNPs) colloidal dispersion was prepared based on the classical method of Turkevich-Frens. ${ }^{24}$

\section{Characterization of gold nanoclusters}

The water solution of the particles was used for characterization. The absorption spectra and emission spectra were obtained with a UV-visible spectrometer (UV-2450, Shimadzu Corp, Kyoto, Japan) and F-7000 Fluorescence Spectrophotometer (Hitachi Ltd, Tokyo, Japan), respectively. DLS and zeta potential analyses of the AuNCs and RDPAuNCs solutions were measured using a Zetasizer Nano ZS (Malvern Instruments Ltd, Malvern, UK). FTIR spectroscopy (IR Prestige-21, Shimadzu Corp) was used to verify the attachment of peptides to the surface of the AuNCs. For the gel electrophoresis, RDP-AuNCs and AuNCs were loaded on $1 \%(\mathrm{w} / \mathrm{v})$ agarose gel for 10 minutes at $100 \mathrm{~V}$ in $0.5 \times$ Tris base, acetic acid, and ethylenediaminetetraacetic acid (TAE) buffer. After migration, the bands were visualized on the gel with UV illumination at $365 \mathrm{~nm}$.

\section{Cell culture}

Human lung adenocarcinoma epithelial cells (A549) were cultured in Roswell Park Memorial Institute (RPMI)-1640 medium, and human neuroblastoma cells (SH-SY5Y) were cultured in Dulbecco's Modified Eagle's Medium (DMEM) and F-12 medium with the ratio of $1: 1$. For the glioblastoma cell line (U87), DMEM was used as the culture medium. All mediums were obtained from Gibco and supplemented with $10 \%$ fetal bovine serum (FBS), $100 \mathrm{IU} / \mathrm{mL}$ penicillin, $100 \mathrm{mg} / \mathrm{mL}$ streptomycin, and incubated at $37^{\circ} \mathrm{C}$ and $5 \%$ 
$\mathrm{CO}_{2}$ in a humidified environment incubator (CCL-170B-8, ESCO, Timur, Indonesia).

\section{Cellular uptake measurement}

Inverted fluorescence microscopy (IX73, Olympus Corporation, Tokyo, Japan) was used to determine the efficiency of the cellular uptake of AuNCs (without peptide) and RDP-AuNCs. The SH-SY5Y cells were transplanted onto six-well plates at a density of 2,000 cells per well. When the confluence of cells reached $60 \%$, AuNCs and RDP-AuNCs were each added into the respective growth media at different times at a final concentration of $0.12 \mathrm{mg} / \mathrm{mL} .{ }^{25}$ Subsequently, the growth media were removed, and the cells were washed with phosphate-buffered saline (PBS) three times, then 4',6-diamidino-2-phenylindole (DAPI) was added for 4 minutes for nuclei staining. Finally, the cells were observed under a fluorescence microscope and pictures taken with a digital camera.

\section{Localization study of RDP-AuNCs using transmission electron microscopy ${ }^{26,27}$}

SH-SY5Y cells were transplanted onto culture dishes of $8 \mathrm{~cm}$ diameter to form a confluent monolayer and incubated at $37^{\circ} \mathrm{C}$ and $5 \% \mathrm{CO}_{2}$ for 24 hours, and then a certain amount of RDP-AuNCs was added into the medium and further incubated for 2 hours. The cells were harvested with trypsin/ethylene diamine tetraacetic acid (EDTA) solution and fixed with glutaraldehyde $(4 \% \mathrm{w} / \mathrm{v})$ solution for 2 hours followed by washing with PBS (pH 7.4) three times and staining with osmium tetroxide solution $(1 \% \mathrm{w} / \mathrm{v})$ for 15 minutes. Then the cells were washed with PBS and dehydrated using an acetone-PBS mixture, in which the acetone ratio was gradually increased from $50 \%$ to $100 \%$. Subsequently, the cells were embedded into a low viscosity embedding medium (SPON812/acetone $[1: 1, \mathrm{v} / \mathrm{v}])$ to remove the cells into the SPON812, and then kept at $60^{\circ} \mathrm{C}$ for 24 hours for solidification. Sections of $60 \mathrm{~nm}$ thick were cut and loaded onto copper grids, and the samples were stained with uranyl acetate for 10 minutes. Pictures of cellular location of RDP-AuNCs were taken under TEM (H7500, Hitachi Ltd) at an accelerating voltage of $160 \mathrm{kV}$.

\section{Internalization mechanism of RDP-AuNCs}

To determine whether the RDP-AuNCs entered cells by an adenosine triphosphate (ATP)-dependent mechanism, ATP-depletion assay was performed, since this is an easy and reliable method for internalization mechanism study that is certified by Kam et al. ${ }^{28}$ Briefly, SH-SY5Y cells were preincubated with $\mathrm{PBS}$ buffer at $37^{\circ} \mathrm{C}$, which was then supplemented with an ATP-depletion buffer containing $10 \mathrm{mM} \mathrm{NaN}_{3}$ and $6 \mathrm{mM}_{2}$-deoxy-D-glucose. Thirty minutes later, FAM-labeled RDP-AuNCs conjugates was added into the cell culture media.

For $\mathrm{K}^{+}$-depletion assay, ${ }^{29}$ the cells were washed with $\mathrm{K}^{+}$-free buffer containing $140 \mathrm{mM} \mathrm{NaCl}, 20 \mathrm{mM}$ 4-(2hydroxyethyl)-1-piperazineethanesulfonic acid (HEPES), $1 \mathrm{mM} \mathrm{CaCl}_{2}, 1 \mathrm{mM} \mathrm{MgCl}_{2}$, and $1 \mathrm{mg} / \mathrm{mL}$ D-glucose (pH 7.4) to deplete $\mathrm{K}^{+}$, and then incubated in hypotonic $\mathrm{K}^{+}$-free buffer $\left(\mathrm{K}^{+}\right.$-free buffer with $\left.50 \% \mathrm{H}_{2} \mathrm{O}\right)$ and $\mathrm{K}^{+}$-free buffer for 5 minutes and 20 minutes, respectively. After incubation, FAM-labeled RDP-AuNCs conjugates was added into the culture media. The cells were washed and the intensity of cellular fluorescence was observed under microscope.

\section{MTT assay}

The cytotoxicity assay was performed with SH-SY5Y cells and U87 cells by 3-(4,5-dimethylthiazol-2-yl)-2,5diphenyltetrazolium bromide (MTT) assay. Briefly, SH-SY5Y cells were seeded into 96-well plates at a density of 6,000 cells per well, and then cells were incubated in $100 \mu \mathrm{L}$ DMEM containing $10 \%$ FBS for 1 day prior to adding RDP-AuNCs. Then $100 \mu \mathrm{L}$ cell-culturing solutions, a mixture of culture medium and RDP-AuNCs, with different final concentrations of RDP-AuNCs $(0.00,1.25,2.50,5.00 \mathrm{mg} / \mathrm{mL})$ were added and incubated for 24,48 , and 72 hours for each concentration. The cells were then washed with PBS $(100 \mu \mathrm{L}$, three times). $10 \mu \mathrm{L}$ MTT ( $5 \mathrm{mg} / \mathrm{mL}$ in PBS buffer) were added to each solution and further incubated for 4 hours. Finally, the medium was removed and $200 \mu \mathrm{L}$ dimethyl sulfoxide (DMSO) was added. The absorbance was measured at $490 \mathrm{~nm}$ using a microplate reader (Model 680, Bio-Rad Laboratories Inc., Hercules, CA, USA). The relative cell viability was calculated as cell viability $(\%)=$ optical density at wavelength of $490 \mathrm{~nm}$ $\left(\mathrm{OD}_{490}\right)$ (sample-blank)/ $\left(\mathrm{OD}_{490}\right)$ (control-blank). The values were averaged from four independent experiments.

\section{In vivo imaging}

Noninvasive fluorescent imaging was performed using an In-Vivo Imaging System Fx Pro (Carestream Health Inc., Rochester, NY, USA). Null mice (SCXK [Jing 2009-0015]) were purchased from Chongqing Medical University, Chongqing, People's Republic of China. Animals were maintained and used for experiments according to the guidelines of the Institutional Animal Committee of Southwest University, Chongqing, People's Republic of China. 
AuNPs, AuNCs, and RDP-AuNCs were injected into mice via tail veins at a dose of $10 \mathrm{mg}$ per kilogram of body weight. ${ }^{30}$ Then, the mice were anesthetized with $4 \%$ chloral hydrate 1 hour following injection. Afterwards, each mouse was placed in the cassette of an imaging instrument, and images were captured with X-ray and fluorescence (excitation wavelength $[\mathrm{EX}]=610 \mathrm{~nm}$; emission wavelength $[E M]=790 \mathrm{~nm}$ ), and then overlaid according to the protocol of the manufacturer.

\section{Fluorescence co-localization assay in mouse neural cells}

Healthy, male, 8-week-old Kunming species mice were purchased from the Chongqing Medical University (SCXK [Yu 2012-0001]). Animal studies were performed according to the guidelines of the Institutional Animal Committee of Southwest University.

The mice were injected with RDP conjugates via tail veins. Two hours after the injection, the mice were euthanized and the brains were dissected out. The brains were fixed with 4\% paraformaldehyde for 2 hours, and then gradually dehydrated in $0.1 \mathrm{M}$ phosphate buffer containing 10\%, 20\%, and $30 \%$ sucrose overnight at $4{ }^{\circ} \mathrm{C}$. Frozen coronal sections of the cerebrum of $30 \mu \mathrm{m}$ thickness were cut and rinsed in PBS with a cryostat microtome and mounted on slides with DAPI (4,6-diamino-2-phenyl indole) for nuclear staining. The sections were observed with inverted fluorescence microscopy.

\section{Results and discussion}

\section{Appearance and characteristics} of AuNCs and RDP-AuNCs

AuNCs and RDP-AuNCs of less than $10 \mathrm{~nm}$ in diameter were synthesized according to previous reports for the preparation of long-life fluorescence clusters. ${ }^{31}$ The RDP peptide might attach to the AuNCs by electrostatic force, since RDP is a cationic peptide with isoelectric point (pI) 12.7, and BSA on the AuNCs is a negatively charged protein with pI 4.6. The aqueous solution of AuNCs appeared brown under visible light and the freeze-dried powder emitted reddish-brown fluorescence under UV light (Figure 1A), while the FAMRDP-AuNCs solution showed a yellowish-brown color and the powder emitted a yellow fluorescence under UV light (Figure 1A). Additionally, the results of gel electrophoresis indicated that FAM-RDP-AuNCs have a lower mobility than AuNCs, which is perhaps related to the larger size and positively charged RDP of the FAM-RDP-AuNCs (Figure 1B).
DLS and zeta-potential analysis were determined through cumulant fit, and the material refractive index (RI) and dispersant RI were 1.59 and 1.33 , respectively. The material absorption of both AuNCs and RDP-AuNCs was 0.01. The results also showed that the average size of the AuNCs was $8.00 \pm 0.72 \mathrm{~nm}$ (Z-average) with a polydispersity index (PDI) of 0.332 and zeta potential of $-17.50 \pm 1.25 \mathrm{mV}$, while the RDPAuNCs had an average size of $10.00 \pm 2.85 \mathrm{~nm}$ (Z-average), PDI of 0.346 , and zeta potential of $-5.92 \pm 3.16 \mathrm{mV}$ (Figure 1C). The curve of FTIR spectra suggests that the structure of the RDP-AuNCs conjugates had changed from that of the AuNCs (Figure 1D). Theoretically, if the size of the AuNCs is $10 \mathrm{~nm}$, an average of about 33 RDPs will attach to each particle. Additionally, the maximum peaks of both the AuNCs and FAM-RDP-AuNCs was $670 \mathrm{~nm}$ when the excitation wavelength was $510 \mathrm{~nm}$, while the fluorescence intensity markedly increased as the RDP linked with the AuNCs (Figure 1E).

The curve of absorption spectra of RDP-AuNCs showed that the plasmon band of absorbance increased slightly, and the maximum absorbance appeared red-shifting when RDP was conjugated to AuNCs (Figure 1F), which could be related to the slight increase in the size of the RDP-AuNCs, and indicates the successful synthesis of RDP-AuNCs.

\section{RDP-AuNCs specifically enter the neural cells}

To determine whether RDP-AuNCs could enter the neural cells, we first compared the cellular transport efficacy of AuNCs with that of RDP-AuNCs. The results showed a strong red fluorescence appearing in the RDP-AuNCs-treated SH-SY5Y cells, whereas a relatively weak fluorescence was detected in the AuNCs-treated cells after 40 minutes of co-incubation (Figure 2A), suggesting that RDP, a type of cell-penetrating peptide (CPP), has the capability to increase cellular uptake of its payload. We assume that the presence of RDP on the nanoparticle surfaces is what promoted the cellular transport, which is consistent with a previous report. ${ }^{32}$ To further identify the cell specificity of the RDP-AuNCs, one type of non-neuronal cell, human lung A549, was used to compare the internalization efficacy with that of a neural cell, SH-SY5Y. The results showed that the fluorescence intensity of RDP-AuNCs-treated A549 cells was far lower than that of RDP-AuNCs-treated SH-SY5Y (Figure 2B). The intrinsic high affinity of RDP to neural cells has been suggested in previous reports, in which rhodamine labeled RDP can enter into the neural cells, probably due 
A

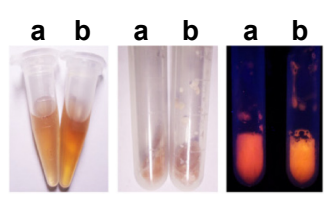

D

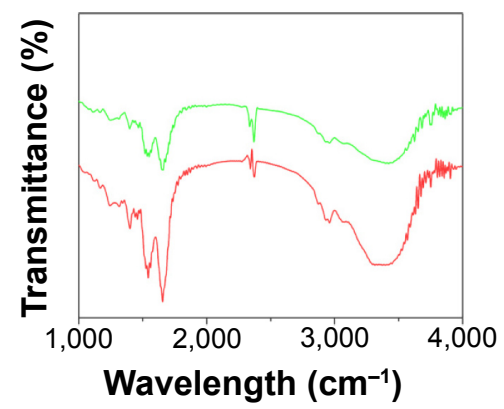

$\mathbf{E}$

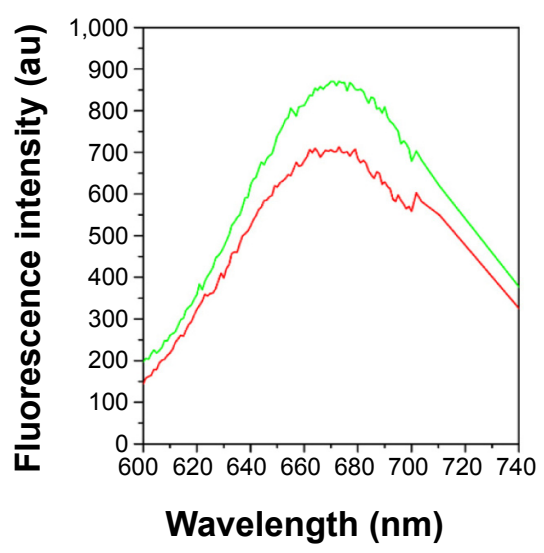

C
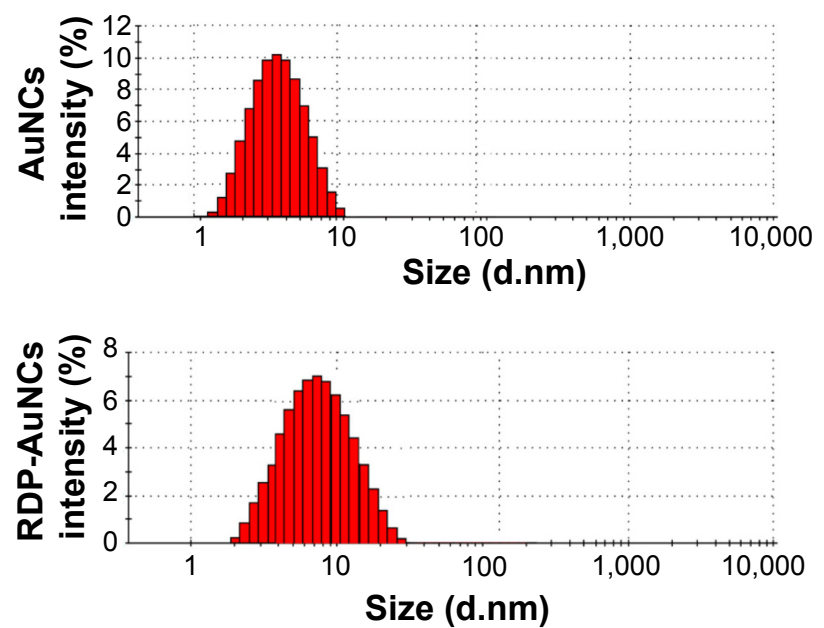

$\mathbf{F}$

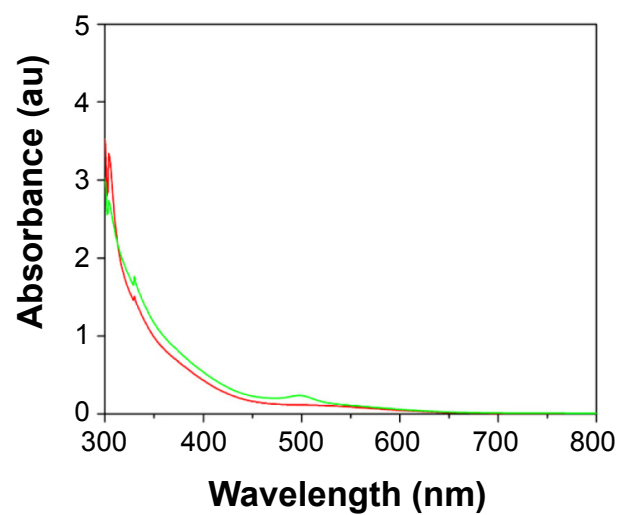

Figure I The characterization of gold nanoclusters (AuNCs) and RDP-AuNCs.

Notes: (A) Appearance and electrophoretic analysis of AuNCs and FAM-RDP-AuNCs. Aqueous solution and powder under visible and ultraviolet light (365 nm). (a) AuNCs; (b) FAM-RDP-AuNCs. The left figure is aqueous solution, the middle is powder under visible light, and the right figure is powder under ultraviolet light. (B) Electrophoretic mobility of AuNCs (Lane I) and FAM-RDP-AuNCs (Lane 2) in agarose gel. (C) Size distribution of AuNCs and RDP-AuNCs determined by dynamic light scattering. (D) Fourier-transform infrared spectra of AuNCs and RDP-AuNCs. (E) Fluorescence of AuNCs and RDP-AuNCs ( $\lambda$ ex=5I0 nm). (F) Absorption spectra of AuNCs and RDPAuNCs. Red curve: AuNCs; green curve: RDP-AuNCs.

Abbreviations: AuNCs, gold nanoclusters; FAM, carboxyfluorescein; RDP, rabies virus glycoprotein derived peptide.

to interaction between RDP and the gamma aminobutyric acid (GABA) receptor of the cell membrane. ${ }^{21}$ The time course of FAM-RDP-AuNCs in SH-SY5Y cells suggested that FAM-RDP-AuNCs can enter into the cells within 30 minutes, and the fluorescence was distributed throughout the whole cells. However, the fluorescence was relatively stronger in the cytoplasm than the nucleus after 1 hour's incubation. There was very weak fluorescence that could be detected after 72 hours, which suggests that the conjugate can last for a long time in the cells (Figure 2C). Additionally, glioma cell line (U87) imaging was also undertaken in this study because gliomas are the most common brain tumor. The results show that the RDP-AuNCs could internalize to U87 cells with high efficiency (Figure 3).
To determine the cytotoxicity, the RDP-AuNCs were added into cell media to be different final concentrations of $0.00,1.25,2.50$, and $5.00 \mathrm{mg} / \mathrm{mL}$. The different groups of each concentration were then incubated for 24,48 , and 72 hours, the absorbance was recorded according to the MTT method. The results indicate that cell viability decreased following increase in RDP-AuNCs concentration, but cell viability was $85.7 \%$ and $86.6 \%$ for $\mathrm{SH}-$ SY5Y and U87, respectively, after 72 hours' incubation when the concentration reached $1.25 \mathrm{mg} / \mathrm{mL}$ (Figure 4). Compared with the high concentration of RDP-AuNCs in the cytotoxicity study, a concentration of only $0.12 \mathrm{mg} / \mathrm{mL}$ was used in imaging, which means that the particles are biosafe for application. 
A

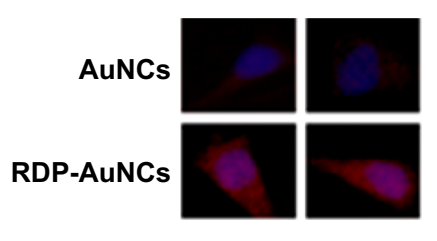

B

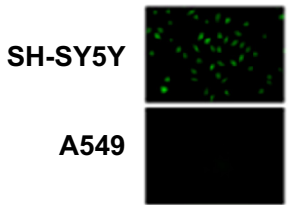

DAPI

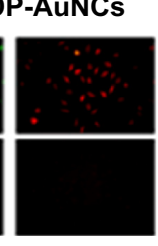

Merge

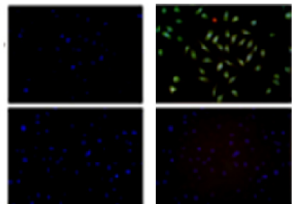

C optical light

light FAM-RDP-AUNCS

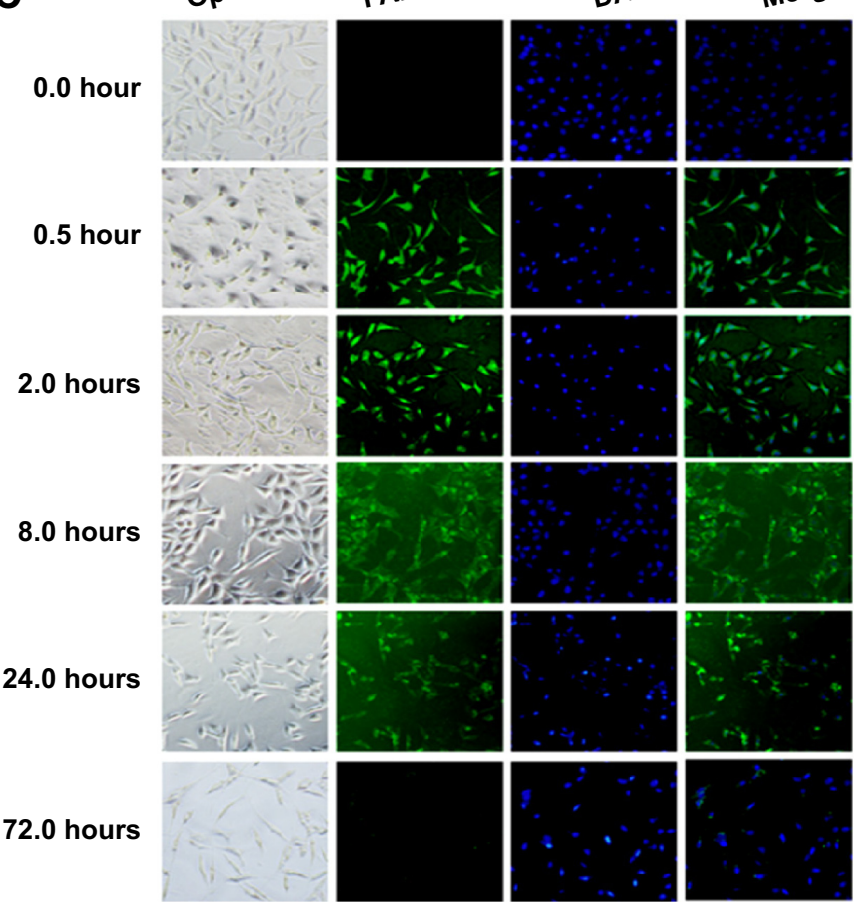

Figure 2 Cellular uptake analysis.

Notes: (A) Fluorescence images of SH-SY5Y cells treated with gold nanoclusters (AuNCs) or RDP-AuNCs. Nuclei (blue) were stained with 4',6-diamidino-2-phenylindole (DAPI). (B) Cellular uptake specificity of AuNCs (red) conjugated with FAM-RDP (green) into neural cells. (C) Time course of intracellular accumulation of FAM-labeled RDP-AuNCs observed under fluorescence microscopy.

Abbreviation: AuNCs, gold nanoclusters; FAM, carboxyfluorescein; RDP, rabies virus glycoprotein derived peptide.

\section{Internalization mechanism of RDP-AuNCs}

Generally, there are two types of internalization mechanism that are involved in the cellular uptake of high-molecularweight compounds: direct penetration and endocytosis, where the former is ATP independent and the latter is not. ${ }^{33}$ In this study, we used ATP-depleted buffer as cell culture medium at $4^{\circ} \mathrm{C}$ to determine whether the uptake is dependent on energy. It was found that the fluorescence intensity of RDP-AuNCs-treated ATP-depleted cells was significantly decreased, as observed by the fluorescence microscopy, resulting from the $\mathrm{NaN}_{3}$ that disturbed the production of ATP (Figure 5A).
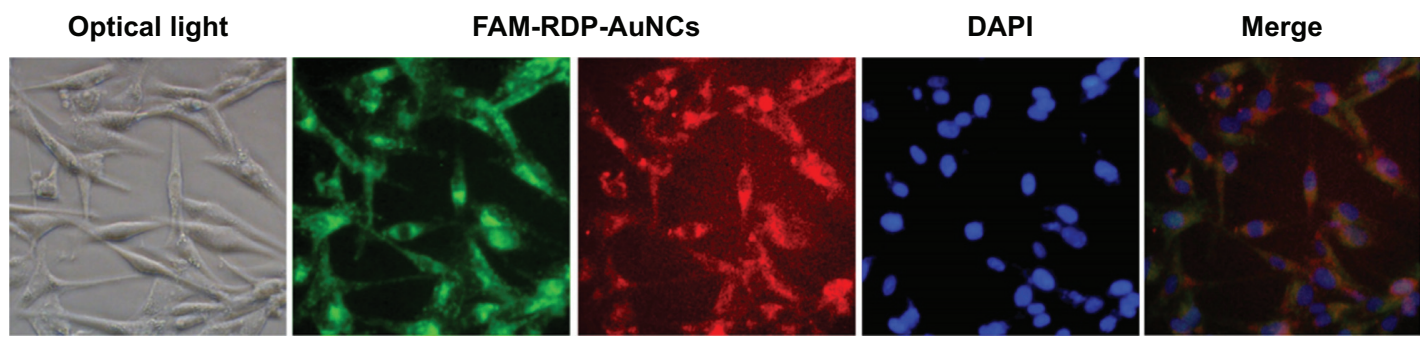

Figure 3 Cellular uptake of FAM-RDP-AuNCs in gliomas cell lines (U87) after 8 hours' incubation. Nuclei were stained with 4',6-diamidino-2-phenylindole (DAPI). Abbreviations: AuNCs, gold nanoclusters; FAM, carboxyfluorescein; RDP, rabies virus glycoprotein derived peptide. 
A

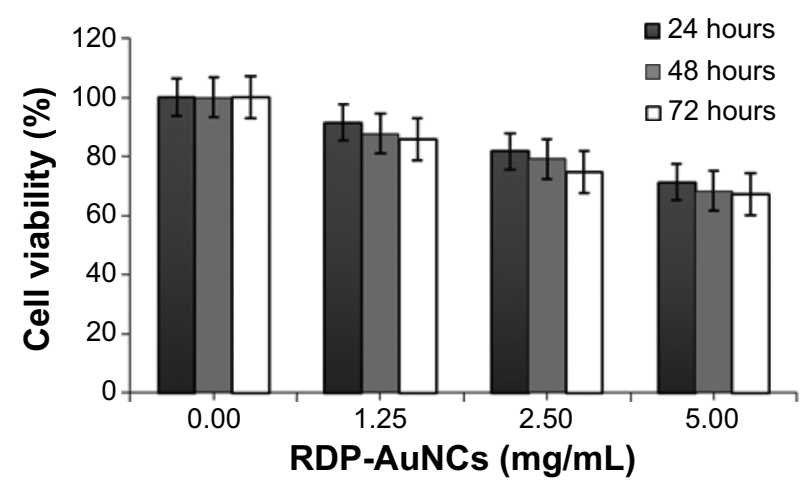

B

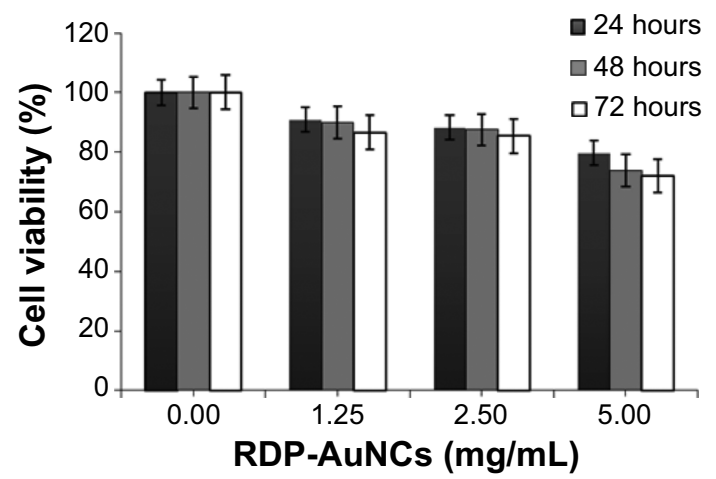

Figure 4 In vitro cytotoxicity assay of RDP-AuNCs in (A) SH-SY5Y cells and (B) U87 cells by 3-(4,5-dimethylthiazol-2-yl)-2,5-diphenyltetrazolium bromide (MTT) assay. Note: Data are expressed as mean \pm standard error of the mean $(n=4)$.

Abbreviations: AuNCs, gold nanoclusters; RDP, rabies virus glycoprotein derived peptide.

Since receptor-mediated endocytosis through clathrincoated pits is the most common manner of endocytosis, ${ }^{34}$ and previous studies have shown that the $\mathrm{K}^{+}$depletion of cells will lead to the disappearance of coated pits from the cell surface by disassembling the clusters of receptors with coated pits, and then inhibiting receptor-mediated endocytosis, ${ }^{29}$ here clathrin-dependent endocytosis was identified using $\mathrm{K}^{+}$-depleted medium for cell culture. The results are shown
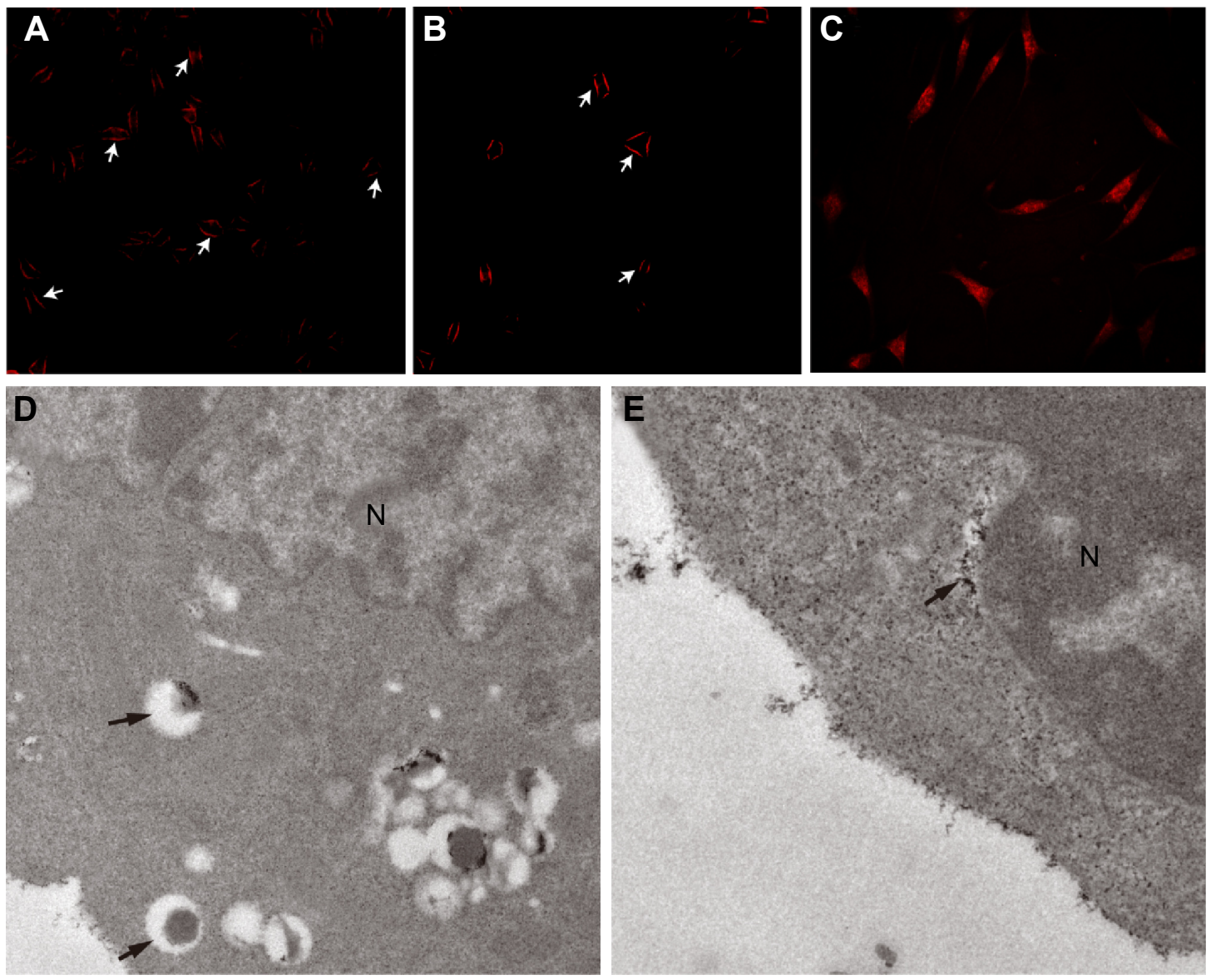

Figure 5 Internalization mechanism of RDP-AuNCs.

Notes: (A) Pretreatment with ATP-depletion buffer; (B) treatment with $\mathrm{K}^{+}$-depletion buffer. In (A,B) the arrows point to the attachment of RDP-AuNCs on the cell membrane; (C) normal; (D) RDP-AuNCs entrapped in the endosome under transmission electron microscopy (TEM). The arrows point to the RDP-AuNCs trapped in the endosome. (E) no endosome was observed in the cells after 2 hours. The arrows point to the RDP-AuNCs dispersed in the cytoplasm.

Abbreviations: AuNCs, gold nanoclusters; ATP, adenosine triphosphate; N, nucleus under TEM; RDP, rabies virus glycoprotein derived peptide. 
in Figure 5B. The fluorescence of RDP-AuNCs-treated $\mathrm{K}^{+}-$ depleted cells can be seen to be much lower than that of the normal treated cells (Figure 5C), and the pictures show that the RDP-AuNCs conjugates only bound to the cell membrane and lost its cell penetration ability.

To further confirm the internalization mechanism of RDP-AuNCs, TEM was used to determine the location of the RDP-AuNCs in cells. Previous reports have suggested that an endocytosis-mediated mechanism is involved in the internalization of AuNPs with a ligand shell containing CPPs, and the stable particles were observed in the endosome in the early period of cellular uptake, and then the particles were rapidly released into the cytoplasm, as the positive charge of CPPs destroy the endosome membrane..$^{35,36}$ In this study, TEM revealed that the RDP-AuNCs conjugates was taken up by the cells, and trapped in the endosome 10 minutes after incubation with cells (Figure 5D). At the 2-hour time point, they were distributed in the cytoplasm (Figure 5E), which we assumed the reason of this phenomenon was because of the conjugate being released from the endosome due to the strong positive charges of RDP (pI 12.7).

\section{In vivo imaging of RDP-AuNCs}

Although nanoparticles of about $10 \mathrm{~nm}$ can permeate through the BBB, they have no tissue specificity and only a small amount can be detected in the brain. ${ }^{37}$ In this study, we examined whether RDP-AuNCs were capable of concentrating in the mouse brain and being used as an imaging candidate. The mice were injected with either RDP-AuNCs, AuNCs, or AuNPs via the tail vein, and images were taken 1 hour after administration. Here, the AuNPs without native fluorescence, which were were fabricated by the Turkevich-Frens method and had a size of $18 \mathrm{~nm}$ and zeta potential of $-39.26 \mathrm{mV}$, were used as the blank control. Strong signals were detected in the brains of RDP-AuNCs-treated mice, relatively weak signals appeared in the corresponding AuNCs-treated mice, and there were no signals in the AuNPs-treated mice, though the studies were performed in parallel (Figure 6A).
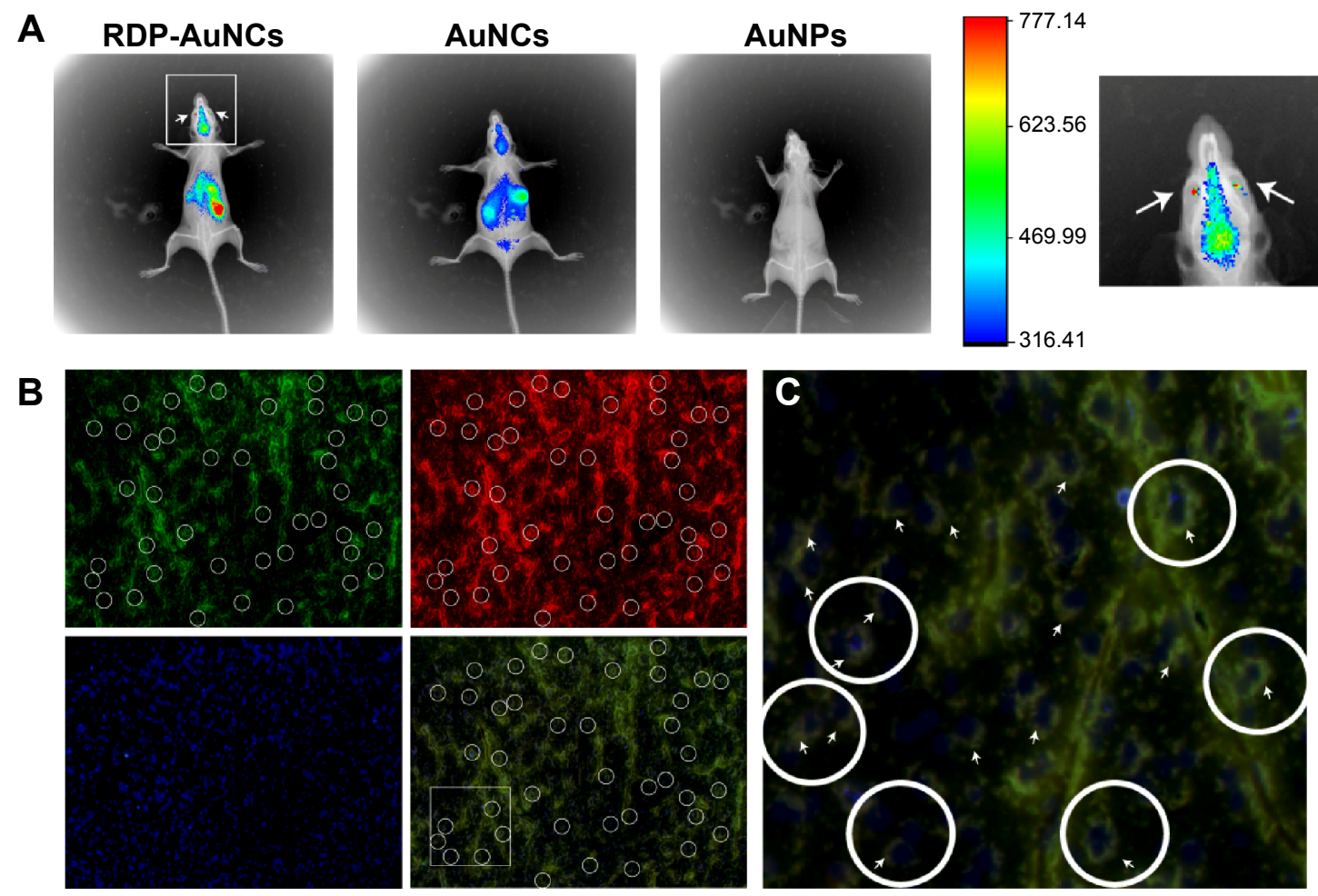

Figure 6 In vivo imaging of RDP-AuNCs.

Notes: (A) Noninvasive imaging I hour after intravenous (IV) injection into the tail vein of RDP-AuNCs, gold nanoclusters (AuNCs), and gold nanoparticles (AuNPs), respectively. (B) The mouse brain was dissected to take slices at 2 hours after IV injection with FAM-RDP-AuNCs. Green spots represent the fluorescence from FAM of FAM-RDP-AuNCs; red spots represent fluorescence from nanoclusters of FAM-RDP-AuNCs; 4',6-diamidino-2-phenylindole (DAPI)-stained nuclei appear blue. Merge of images; (C) magnification of circles of merge images. The arrows point to FAM-RDP-AuNC fluorescence.

Abbreviations: AuNCs, gold nanoclusters; FAM, carboxyfluorescein; RDP, rabies virus glycoprotein derived peptide. 
Notably, the distribution of RDP-AuNCs in vivo showed that there was a high fluorescence signal in the eyes of mice (arrows in Figure 6A), suggesting that the conjugate can pass through the blood-retinal barrier. This finding is similar to that of a previous study, in which $20 \mathrm{~nm}$ AuNPs could pass through the blood-retinal barrier and distribute in all retinal layers. ${ }^{38}$

To further determine if neural cells could be imaged with RDP-AuNCs, the fluorescence co-location of the RDP (green) and AuNCs (red) of the FAM-RDP-AuNCs conjugates was identified. The results indicated that FAM-RDP-AuNCs crossed the BBB and entered the neural cells (Figure 6B), and the fluorescence was located in the cytoplasm 2 hours after injection (white circles in Figure 6C). Another advantage of RDP-AuNCs in imaging was that near-infrared fluorescence emitted by AuNCs could significantly improve the signalto-background ratio and enhance the fluorescence intensity of deep tissues. ${ }^{39}$ Additionally, it is possible for RDP-AuNCs to be used in brain-tumor (including glioma) imaging due to passive targeting (vascular proliferation of tumors). ${ }^{40}$

\section{Conclusion}

In this study, the feasibility of RDP-AuNCs for neural-cell imaging was determined in cell to animal studies. Noninvasive imaging of, and biodistribution in, the brain show that these clusters can be delivered into the brain with high efficiency. All these results show that the RDP-AuNCs can be a potential candidate for imaging. RDP-AuNCs can increase cellular uptake, and the internalization mechanism of neural cells was detected by $\mathrm{K}^{+}$-depletion assay and ATP-depletion assay, suggesting that the receptor-mediated clathrin-coated pits could be one intrinsic pathway for RDP-AuNCs penetration. The time course of RDP-AuNCs in neural cells also indicated that this conjugate can be maintained in the cells for 3 days. Therefore, RDP-AuNCs might be an effective and specific imaging candidate for neural cells.

\section{Acknowledgments}

This work was supported by grants from the Natural Science Foundation of China (81273416); the Scientific Research Foundation for Returned Scholars, Ministry of Education of China (2012-940), the Fundamental Research Funds for the Central Universities (XDJK2013A030); and the New Century Excellent Talents in University Award, Ministry of Education of China.

\section{Disclosure}

The authors report no conflicts of interest in this work.

\section{References}

1. Tada M, Takeuchi A, Hashizume M, Kitamura K, Kano M. A highly sensitive fluorescent indicator dye for calcium imaging of neural activity in vitro and in vivo. Eur J Neurosci. 2014;39(11):1720-1728.

2. Sato TR, Gray NW, Mainen ZF, Svoboda K. The functional microarchitecture of the mouse barrel cortex. PLoS Biol. 2007;5(7):e189.

3. Ikegaya Y, Le Bon-Jego M, Yuste R. Large-scale imaging of cortical network activity with calcium indicators. Neurosci Res. 2005;52(2): 132-138.

4. Abbott NJ, Patabendige AA, Dolman DE, Yusof SR, Begley DJ. Structure and function of the blood-brain barrier. Neurobiol Dis. 2010;37(1): $13-25$.

5. Ulbrich K, Hekmatara T, Herbert E, Kreuter J. Transferrin- and transferrin-receptor-antibody-modified nanoparticles enable drug delivery across the blood-brain barrier (BBB). Eur J Pharm Biopharm. 2009;71(2):251-256.

6. Kreuter J. Nanoparticulate systems for brain delivery of drugs. $A d v$ Drug Deliv Rev. 2001;47(1):65-81.

7. De M, Ghosh PS, Rotello VM. Applications of nanoparticles in biology. Adv Materials. 2008;20(22):4225-4241.

8. Retnakumari A, Setua S, Menon D, et al. Molecular-receptor-specific, non-toxic, near-infrared-emitting Au cluster-protein nanoconjugates for targeted cancer imaging. Nanotechnology. 2010;21(5):055103.

9. Chen H, Li S, Li B, et al. Folate-modified gold nanoclusters as nearinfrared fluorescent probes for tumor imaging and therapy. Nanoscale. 2012;4(19):6050-6064.

10. Wang Y, Chen JT, Yan XP. Fabrication of transferrin functionalized gold nanoclusters/graphene oxide nanocomposite for turn-on near-infrared fluorescent bioimaging of cancer cells and small animals. Anal Chem. 2013;85(4):2529-2535.

11. Lin CA, Yang TY, Lee CH, et al. Synthesis, characterization, and bioconjugation of fluorescent gold nanoclusters toward biological labeling applications. ACS Nano. 2009;3(2):395-401.

12. Kuan GC, Sheng LP, Rijiravanich P, et al. Gold-nanoparticle based electrochemical DNA sensor for the detection of fish pathogen Aphanomyces invadans. Talanta. 2013;117:312-317.

13. Jang B, Park JY, Tung CH, Kim IH, Choi Y. Gold nanorod-photosensitizer complex for near-infrared fluorescence imaging and photodynamic/ photothermal therapy in vivo. ACS Nano. 2013;5(2):1086-1094.

14. De Jong WH, Hagens WI, Krystek P, Burger MC, Sips AJ, Geertsma RE. Particle size-dependent organ distribution of gold nanoparticles after intravenous administration. Biomaterials. 2008;29(12):1912-1919.

15. Venkatesh V, Shukla A, Sivakumar S, Verma S. Purine-stabilized green fluorescent gold nanoclusters for cell nuclei imaging applications. ACS Appl Mater Interfaces. 2014;6(3):2185-2191.

16. Palmal S, Basiruddin SK, Maity AR, Ray SC, Jana NR. Thiol-directed synthesis of highly fluorescent gold clusters and their conversion into stable imaging nanoprobes. Chemistry. 2013;19(3):943-949.

17. Wang HH, Lin JC, Lee $\mathrm{CH}$, et al. Fluorescent gold nanoclusters as a biocompatible marker for in vitro and in vivo tracking of endothelial cells. ACS Nano. 2011;5(6):4337-4344.

18. Wong OA, Hansen RJ, Ni TW, et al. Structure-activity relationships for biodistribution, pharmacokinetics, and excretion of atomically precise nanoclusters in a murine model. Nanoscale. 2013;5(21): $10525-10533$.

19. Fu A, Wang Y, Zhan L, Zhou R. Targeted delivery of proteins into the central nervous system mediated by rabies virus glycoprotein-derived peptide. Pharm Res. 2012;29(6):1562-1569.

20. Tuffereau C, Benejean J, Alfonso AR, Flamand A, Fishman MC. Neuronal cell surface molecules mediate specific binding to rabies virus glycoprotein expressed by a recombinant baculovirus on the surfaces of lepidopteran cells. J Virol. 1998;72(2):1085-1091.

21. Fu A, Zhao Z, Gao F, Zhang M. Cellular uptake mechanism and therapeutic utility of a novel peptide in targeted-delivery of proteins into neuronal cells. Pharm Res. 2013;30(8):2108-2117. 
22. Fu A, Zhang M, Gao F, Xu X, Chen Z. A novel peptide delivers plasmids across blood-brain barrier into neuronal cells as a single-component transfer vector. PloS One. 2013;8(3):e59642.

23. Xie J, Zheng Y, Ying JY. Protein-directed synthesis of highly fluorescent gold nanoclusters. J Am Chem Soc. 2009;131(3):888-889.

24. Jiang XM, Wang LM, Wang J, Chen CY. Gold nanomaterials: preparation, chemical modification, biomedical applications and potential risk assessment. Appl Biochem Biotechnol. 2012;166(6):1533-1551.

25. Chen WH, Chen JX, Cheng H, et al. A new anti-cancer strategy of damaging mitochondria by pro-apoptotic peptide functionalized gold nanoparticles. Chemical Commun (Camb). 2013;49:6403-6405.

26. Yamada M, Oeda A, Jung J, et al. Hepatitis B virus envelope L proteinderived bio-nanocapsules: mechanisms of cellular attachment and entry into human hepatic cells. J Control Release. 2012;160(2):322-329.

27. Sonavane G, Tomoda K, Makino K. Biodistribution of colloidal gold nanoparticles after intravenous administration: effect of particle size. Colloids Surf B Biointerfaces. 2008;66(2):274-280.

28. Kam NW, Liu Z, Dai H. Carbon nanotubes as intracellular transporters for proteins and DNA: an investigation of the uptake mechanism and pathway. Agnew Chem Int Ed Engl. 2006;45(4):577-581.

29. Larkin MJ, Donzell WC, Anderson RG. Potassium-dependent assembly of coated pits: new coated pits form as planar clathrin lattices. $J$ Cell Biol. 1986;103(6 Pt 3):2619-2627.

30. Luo Z, Zheng K, Xie J. Engineering ultrasmall water-soluble gold and silver nanoclusters for biomedical applications. Chemical Commun (Camb). 2014;50:5143-5155.

31. Raut S, Chib R, Rich R, Shumilov D, Gryczynski Z, Gryczynski I. Polarization properties of fluorescent BSA protected Au25 nanoclusters. Nanoscale. 2013;5(8):3441-3446.
32. Prades R, Guerrero S, Araya E, et al. Delivery of gold nanoparticles to the brain by conjugation with a peptide that recognizes the transferrin receptor. Biomaterials. 2012;33(29):7194-7205.

33. Marsh M, McMahon HT. The structural era of endocytosis. Science. 1999;285(5425):215-220.

34. Oh N, Park JH. Endocytosis and exocytosis of nanoparticles in mammalian cells. Int J Nanomedicine. 2014;9 Suppl 1:51-54.

35. Erazo-Oliveras A, Muthukrishnan N, Baker R, Wang TY, Pellois JP. Improving the endosomal escape of cell-penetrating peptides and their cargos: strategies and challenges. Pharmaceuticals (Basel). 2012;5(11): 1177-1209.

36. Lin J, Zhang H, Chen Z, Zheng Y. Penetration of lipid membranes by gold nanoparticles: insights into cellular uptake, cytotoxicity, and their relationship. ACS Nano. 2010;4(9):5421-5429.

37. Khlebtsov N, Dykman L. Biodistribution and toxicity of engineered gold nanoparticles: a review of in vitro and in vivo studies. Chem Soc Rev. 2011;40(3):1647-1671.

38. Kim JH, Kim JH, Kim KW, Kim MH, Yu YS. Intravenously administered gold nanoparticles pass through the blood-retinal barrier depending on the particle size, and induce no retinal toxicity. Nanotechnology. 2009;20(50):505101.

39. Rice BW, Cable MD, Nelson MB. In vivo imaging of light-emitting probes. J Biomed Opt. 2001;6(4):432-440.

40. Brannon-Peppas L, Blanchette JO. Nanoparticle and targeted systems for cancer therapy. Adv Drug Deliv Rev. 2013;64(11):206-212.
International Journal of Nanomedicine

\section{Publish your work in this journal}

The International Journal of Nanomedicine is an international, peerreviewed journal focusing on the application of nanotechnology in diagnostics, therapeutics, and drug delivery systems throughout the biomedical field. This journal is indexed on PubMed Central, MedLine, CAS, SciSearch ${ }^{\circledR}$, Current Contents ${ }^{\circledR} /$ Clinical Medicine,

\section{Dovepress}

Journal Citation Reports/Science Edition, EMBase, Scopus and the Elsevier Bibliographic databases. The manuscript management system is completely online and includes a very quick and fair peer-review system, which is all easy to use. Visit http://www.dovepress.com/ testimonials.php to read real quotes from published authors. 